\title{
Biomaterial Scaffolds in Pediatric Tissue Engineering
}

\author{
MINAL PATEL AND JOHN P. FISHER
}

Fischell Department of Bioengineering, University of Maryland, College Park, Maryland 20742

\begin{abstract}
This article reviews recent developments and major issues in the use and design of biomaterials for use as scaffolds in pediatric tissue engineering. A brief history of tissue engineering and the limitations of current tissue-engineering research with respect to pediatric patients have been introduced. An overview of the characteristics of an ideal tissue-engineering scaffold for pediatric applications has been presented, including a description of the different types of scaffolds. Applications of scaffolds materials have been highlighted in the fields of drug delivery, bone, cardiovascular, and skin tissue engineering with respect to the pediatric population. This review highlights biomaterials as scaffolds as an alternative treatment method for pediatric surgeries due to the ability to create a functional cell-scaffold environment. (Pediatr Res 63: 497-501, 2008)
\end{abstract}

$\mathrm{T}_{\mathrm{d}}^{\mathrm{h}}$ he field of tissue engineering involves replacement of damaged or diseased tissue to maintain or improve tissue function. Both engineering and biologic principles are applied to achieve this goal (1-3). Over the years, tissue engineering has evolved from engineering organ tissue to mimicking cellular function. Biomaterials play an important role in advancing the field of tissue engineering and have resulted from a marriage of disciplines including life sciences, medicine, materials science, and engineering. Biomaterials are not new; throughout history there are references to glass eyes and wooden or gold-filled teeth (4-6). A relatively new development, however, is the close working relationships between the above-mentioned disciplines. Biomaterials are regarded as natural or synthetic materials used to replace part of a living system or to function in intimate contact with living tissue. They can serve as a scaffold designed to replace, repair, and sustain organ structures. In the past decade, numerous scaffolds have been developed for a variety of tissue-engineering applications (7-11). However, limitations of the scaffolds involve mechanical material failure, material-associated infection, and immunogenic reaction to implanted materials. Keeping in mind these limitations, scaffolds designed for pediatric applications require further modifications. Over the lifetime of a pediatric patient, the material would have to grow and remodel itself with the changing physiologic and biologic environments. Moreover, after implantation the pediatric patient would be further susceptible to foreign material as the

Received November 1, 2007; accepted December 6, 2007.

Correspondence: John P. Fisher, Ph.D., Fischell Department of Bioengineering, University of Maryland, 3238 Jeong H. Kim Engineering Building (No. 225), College Park, Maryland 20742; e-mail: jpfisher@umd.edu or http://www.ench.umd.edu/ $\sim$ jpfisher

This work was supported by the State of Maryland Department of Business and Economic Development and the National Science Foundation through a CAREER Award (J.P.F., BES 0448684). immune system is not completely developed. However, pediatric patients have exhibited a higher regenerative capacity compared with adults because younger cells have undergone less stress and age damage. This review studies novel biomaterials as scaffolds and pediatric tissue-engineering applications.

\section{CHARACTERISTICS OF AN IDEAL SCAFFOLD}

Before developing a scaffold for any tissue-engineering application, the material and biologic properties have to be evaluated. Initially, depending upon the application, mechanical properties should be studied keeping in mind the surrounding environment of the scaffold once placed in an in vivo system. For example, while developing a scaffold for the mandible bone; the mechanical properties have to be considered as it is one of the strongest bones (12). However, for the orbital bone which is $0.5 \mathrm{~mm}$ thick the mechanical properties do not play a role in scaffold design as it does not bear a large mechanical load (13). Scaffold evaluation also includes studying the correct degradation rate, which is important because as the scaffold degrades it is replaced by natural tissue. Depending upon the type of tissue to be replaced, the degradation rate can be controlled by changing the physical or chemical scaffold properties. Scaffold degradation rate also influences the creation of degradation by-products, which may interfere with the tissue repair process by obstructing tissue growth or causing inflammation $(14,15)$. Scaffold porosity is also important to promote cell proliferation and differentiation and also for exchange of nutrients and metabolites. The surface properties and the ability to mold the scaffold into a specific construct are also critical, and depend upon the specific application. For example, bone tissue engineering typically requires a cube or disc-shaped scaffold (16). Nerve, vascular, and trachea tissue engineering usually requires tube-shaped scaffolds (17). Skin, intestine, and liver tissue engineering generally require scaffolds in the form of a flat matrix (18). Scaffolds are also available in the form of injectable gels, which can be used to fill irregularly shaped defects (19). Once the material properties of the scaffold have been characterized, further biologic testing is required. This includes studying the immune and foreign body reactions, and the implementation of different cells or growth factors to enhance the properties of the scaffold. For pediatric applications, scaffolds should be biocompatible, biodegradable, nonimmunogenic, and nontoxic. They should successfully promote cell growth, differentiation, attachment, and migration and be responsive to growth and development changes. Finally, they should be easy to manufacture, sterilize, and microsurgically implant. 


\section{TYPES OF SCAFFOLDS}

Natural scaffolds. Natural scaffolds are made up of protein or carbohydrates with particular biochemical, mechanical, and structural properties. They can be derived from plant or animal sources, and are mostly found to be both biocompatible and biodegradable. These scaffolds have an increased advantage due to the presence of multifunctional groups on scaffold surfaces, which can be tailored according to specific applications. For example, collagen, chitosan, hyaluronic acid, fibrin, and gelatin are all natural scaffolds, which have been applied for the repair and reconstruction of tissues (20-24). Porcine collagen is a commercially available graft, which has been previously used as a tissue-engineering scaffold. It has also been applied in a pediatric patient to close the anterior abdominal wall after a surgical procedure. The graft was in the form of a sheet, acellular and did not provoke an immune response. After $18 \mathrm{mo}$, the wound had healed and the collagen graft was successfully applied for abdominal wall reconstruction (25).

Hyalomatrix composed of silicone and hyaluronic acid has been previously used to treat pediatric burn patients (26). They successfully covered the dermal plane and actively stimulated spontaneous healing. The matrix had a slow degradation rate compared with the current treatment methods and as a result provided a sufficient time frame for complete wound healing.

Recently, human fibrin was used as a scaffold to culture pediatric auricular chondrocytes to engineer elastic cartilage. Gene expression studies demonstrated that the engineered cartilage resembled the features of native elastic cartilage and could be applied as a scaffold for pediatric ear reconstructive surgery (25). Thus natural scaffolds have been applied for a variety of tissue-engineering applications. However, limitations include the inability to control or modify the chemical and biologic properties of these scaffolds for specific applications. Thus, focus has been placed on synthetic and blended biomaterials.

Synthetic scaffolds. Synthetic biomaterials are being favored as scaffolds as their physical and biologic properties can be modified and they can be reproduced in similar and large quantities. The major classes of synthetic biomaterials include glycolic acid derivatives, lactic acid derivatives, and other polyester derivatives. A study evaluated the potential of a copolymer scaffold of L-lactide and -caprolactone (50:50) seeded with pediatric autologous bone marrow cells for cardiovascular tissue-engineering applications. Two scaffolds were created, one in the form of a conduit for extracardiac total cavopulmonary connection and another in the form of a patch for the repair of congenital heart defects. They were implanted in patients with a median age of $5.5 \mathrm{y}$ and evaluated for a period of 1.3-31.6 mo. At the end of the evaluation period, they observed that the conduits and patches showed normal function comparable with living tissue. Studies with cineangiography or computed tomography indicated no aneurysm formation or calcification. Interestingly, over time the conduit diameter increased, not seen with the current prosthetic implants which need to be replaced as pediatric patients grow. Thus, this is a promising result in the field of pediatric cardiovascular surgery (27). A more recent study created a vascular scaffold with the potential of repair, remodeling, and growth for pediatric cardiovascular tissue-engineering applications. Biodegradable tubular scaffolds were constructed from polyglycolic acid mesh coated with a copolymer of poly [epsilon-caprolactone-L-lactide]. The scaffolds were seeded with a mixed population of smooth muscle cells and endothelial cells cultured from ovine bone marrow-derived vascular cells. These autologous venous conduits were implanted in juvenile lambs and were evaluated up to $30 \mathrm{~d}$ postsurgically. Results indicated the scaffold was unobstructed and no evidence of thrombosis was noted. Histologic results demonstrated that the scaffold wall was composed of neo-tissue made up of residual polymer matrix, mesenchymal cells, and extracellular matrix without evidence of calcification (28). Several other research groups have developed synthetic materials for pediatric tissue-engineering applications (29-32).

Hydrogels. Hydrogels are made up of polymer chains, which swell in an aqueous solution, and can be natural or synthetic in nature. Hydrogels are typically fabricated with thermally, chemically, or photochemically induced radical initiators, forming a covalently bound polymer network (3335 ). These gels are often designed to be biodegradable, as they can be degraded within the body by water or natural enzymes and ultimately absorbed. Hydrogels are typically biocompatible, owing to their large water content, as they do not provoke an immune response and cause inflammation. Thus, hydrogels have been found to possess tissue-like properties as they can be successfully used to encapsulate cells and create a cellscaffold environment $(36,37)$. Hydrogels can also be used in an injectable form to repair irregular shaped defects and for cosmetic surgery. These gels have been extensively studied in drug delivery and cell encapsulation. A more common commercial application of hydrogels is contact lenses. For example, a recent study evaluated the efficacy of an aloe vera hydrogel in the form of a bioadhesive patch for treatment of aphthous stomatitis (mouth ulcers) in pediatric patients. After $2 \mathrm{~d}$ of treatment $74 \%$ of patients indicated a positive improvement in symptoms and after $4 \mathrm{~d}, 80 \%$ of patients indicated a decrease in provoked pain (38). Another hydrogel application, involves the reconstruction of pediatric trachea in athymic mice. The construct was a combination of biodegradable hydrogel (Pluronic F127) and nonbiodegradable high-density polyethylene (HDP) as an internal support in a predetermined trachea shape. A hydrogel-human chrondrocyte mixture was painted onto the HDP surface and was implanted s.c. for a period of $8 \mathrm{wk}$. After implantation, the tissue-engineered trachea construct indicated no inflammation and histology exhibited an increased proteoglycan production. Type II collagen gene expression was also evaluated as it is a major protein in mature cartilage matrix. Increased gene expression was noted in the explanted trachea construct indicating extracellular matrix formation (39). A recent study in Germany evaluated the application of expandable Osmed hydrogels (vinylpyrrolidone and methylmethacrylate) for treatment of cleft palate repair in children. Initial results indicated that palate repair was surgically easier using hydrogel implantation and facial growth distortions may be reduced (40). Injectable hydrogel pellets ( $N$-vinyl pyrrolidone methylmethacrylate) 
have been successfully used for treatment of congenital microphthalmos in pediatric patients (41). Silicone hydrogel contact lenses were also used as a therapeutic treatment for a variety of eye conditions in pediatric patients (42).

\section{APPLICATIONS}

Drug delivery. Drug delivery involves release of a target drug to a specific cell type at a precise and prolonged period of time. Even though numerous drugs are available for use in adults, the majority of these cannot be used in children and pediatricians end up modifying adult dosages for pediatric use. Reasons for these modifications include limited studies involving drug dosage formulations according to age and the lack of suitable drug delivery methods in children. The most common method of drug delivery in children is through needle-vaccinations. Until recently, alternative methods of drug delivery tailored toward the pediatric population have not been pursued due to the small market size, high manufacturing cost, and nonavailability of children in clinical trials due to ethical reasons. Even though numerous therapeutic molecules are being discovered, everyday there is a significant lack of suitable drug delivery methods for the pediatric population. However, a recent study has tried to highlight and approach this problem. The study included the oral delivery of fenretinide ( $N$-(4-hydroxyphenyl) retinamide (4-HPR)) in LYM-XSORB matrix and within a LYM-X-SORB powder. Fenretinide has been shown to reduce or inhibit the growth of tumor cells and LYM-X-SORB is a lipid-based matrix designed to improve the solubility and bioavailability of drugs. Different doses of the drug delivery system were delivered orally in the BALB/c mouse model. The levels of 4 -HPR and $\mathrm{N}$-(4methoxyphenyl)retinamide measured in plasma and tissues increased in both powder and matrix delivery systems compared with delivery through a traditional corn oil capsule. The nude mouse model was used to establish a human neuroblastoma cell line and treated with the drug-matrix or drug-powder. Treatment with the powdered drug delivery system showed an increased mice survival rate, indicating that the drug was bioavailable and bioactive. This study is a step forward toward a successful pediatric drug delivery system (43).

Bone tissue engineering. Bone repair strategies in the pediatric population remain a challenge. Traditional adult treatment options cannot be applied to children as their bones are still in the development stages. Moreover, the thickness of the pediatric bone is thinner compared with adult bone and during surgery long-term survival of the child has to be considered. A recent study applied a scaffold construct consisting of carbonated apatite bone cement with polylactic acid plates for repair of a pediatric skull defect. Thirty-four pediatric patients with skull defects were treated with the scaffold construct and examined at $3 \mathrm{~d}$ and 3 mo postoperatively using computer tomography scans. After implantation, the construct was not associated with dislodgement, infection, or formation of local hematomas or seromas. A follow-up after 60 mo indicated no complications or failures after surgery in any patient (44). As the pediatric bone is still developing, osteointegration of the scaffold material has to be considered during treatment of bone defects. For pediatric skull repair, osteogenesis was induced by transplanting autologous bone marrow cells. The autologous bone marrow mononucleated cells were seeded onto a freeze-dried collagen matrix associated with a nonceramic hydroxyapatite scaffold. This scaffold was sandwiched between two sheets of polylactic copolymer material. The complete scaffold was applied to repair cranial skull defects in four pediatric patients. Initial results indicated rapid bone osteogenesis and a reduction in the size of skull defect (45). A recent case report described the use of a combination of Gore-Tex Dualmesh plus biomaterial and mandibular multiperforated titanium plates with screws to repair the anterior chest wall. The repair was performed on a $16 \times 8 \mathrm{~cm}$ defect after a tumor had been resected from the sternum. The scaffold was smooth and inert on the inner surface, which did not allow tissue in-growth, and the outer surface was textured, which promoted increased tissue incorporation. Results indicated that the reconstructed chest wall had no deformities and was not associated with any respiratory infections (46). A granulated biocomposite material GAP-00 had been used to repair jaw lesions in pediatric patients. Long-term results indicated improved cosmetic and functional outcomes and full rehabilitation was achieved (47).

Cardiovascular tissue engineering. Congenital cardiovascular diseases affect a large population of children. Cardiovascular tissue engineering in the pediatric population involves replacement of damaged vessels, and heart valves. A number of scaffolds have been used for cardiovascular reconstruction in pediatric patients with complex congenital heart defects. A recent study evaluated a biodegradable polyester urethane scaffold to repair a ventricular tract defect in adult rats. The scaffold was an elastic porous material designed to facilitate cellular in-growth during the healing process. Thus, this attempts to overcome the problem of the current scaffolds, which do not grow with children. After surgery, the scaffold material was completely encapsulated with fibrous tissue, thrombosis was not noted and fibroblastic growth increased with time. Recent studies have also been focusing on applying a cell-scaffold matrix for cardiovascular tissue engineering. Bone marrow-derived mesenchymal cells cultured on a polyglycolic acid and poly-4-hydroxybutyrate scaffold was developed as a tissue-engineered trileaflet heart valve. Histologic studies exhibited increased cellular confluency on the scaffold surface. Biomechanical properties of the scaffold were similar to the native heart valve leaflets (48). Umbilical cord bloodderived endothelial progenitor cells have also been seeded onto a biodegradable vascular scaffold (polyglycolic-acid). Scaffold analysis indicated increased cell to polymer attachment and proliferation. Immunohistochemistry revealed cellular expression of endothelial phenotype (49). A more recent study applied similar cell source toward developing a trileaflet heart valve scaffold (50). Thus, the cell-scaffold approach may be a potential treatment option for the repair of congenital defects.

Skin tissue engineering. Majority of skin tissue-engineering research for pediatric patients involves treatment of second degree burns as they are the second leading cause of death in children under the age of 5 (51). Current treatment methods 
involve the application of autograft, which does not always lead to an ideal repair. Recently, commercial treatment options include Biobrane, Integra artificial dermis, Mepitel and TransCyte. Biobrane is a tissue-engineered biocomposite consisting of silicone and nylon fabric with chemically bound porcine dermal collagen. One study compared the repair of pediatric burns between Biobrane and Duoderm. Duoderm is a dressing commonly used to heal ulcers or acne. Both dressings healed the burns in comparable time and no difference was noted in pain scores. However, Biobrane was found to be more expensive than Duoderm (52). A similar study investigated the use of Biobrane in treatment of burn and scald injuries in pediatric patients (53). The dressing is usually removed after $7-14 \mathrm{~d}$ after tissue healing is noted. The Integra artificial dermis is a tissue-engineered porous matrix composed of cross-linked bovine tendon collagen and glycosaminoglycan and a silicone layer. Pediatric reconstructive surgery was performed on 11 patients using this matrix. Infection and hypertrophic scars was noted in 2 of the patients. In the remaining patients, cosmetic appearance was excellent (54). A more recent study investigated the use of TransCyte a tissueengineered skin substitute. TransCyte consists of a polymer membrane and newborn human fibroblast cells cultured under aseptic conditions in vitro on a nylon mesh. The bioengineered skin substitute was used to treat partial thickness burns in pediatric patients. Increased skin tissue healing was observed in $7.5 \mathrm{~d}$ for the TransCyte group compared with $9.5 \mathrm{~d}$ for Biobrane group. The TransCyte dressing also required less autografting compared with the Biobrane group (55). However, the cost of TransCyte is more than Biobrane dressing. Most of the above mentioned commercial treatments are applied for intermediate burns. For more complex deep partial thickness burns, other tissue-engineering alternatives are being researched. One of the most researched areas is the use of tissue-engineered fetal skin scaffolds. Donated fetal skin grafts are used to culture fetal skin cells, which are seeded onto collagen sheets. The resulting fetal skin scaffold is then directly applied for treatment of burns. A recent clinical trial included eight pediatric patients in treatment of second-degree burns using fetal skin constructs. Results indicated complete healing and no need for autografting, thus indicating the potential of fetal skin constructs in skin tissue engineering (56).

\section{SUMMARY}

Biomaterials are available or can be produced synthetically with a variety of different chemical, mechanical, and biologic properties. For pediatric tissue-engineering applications, scaffolds have to undergo structural and biologic modifications to meet the developmental changes in children. Tissue engineering along with integration of mechanical and chemical engineering can be an ideal solution to pediatric disorders. Biomaterials as scaffolds can attempt to successfully create a regenerative cell or growth factor or drug scaffold environment depending upon the respective application. Through the integration of tissue engineering and medical surgeons, many pediatric surgical problems may be solved.

\section{REFERENCES}

1. Langer R 2000 Tissue engineering. Mol Ther 1:12-15

2. Langer R, Vacanti JP 1993 Tissue engineering. Science 260:920-926

3. Vacanti JP, Langer R 1999 Tissue engineering: the design and fabrication of living replacement devices for surgical reconstruction and transplantation. Lancet 354:SI32-SI34

4. Cima LG, Vacanti JP, Vacanti C, Ingber D, Mooney D, Langer R 1991 Tissue engineering by cell transplantation using degradable polymer substrates. J Biomech Eng 113:143-151

5. Demann ET, Stein PS, Haubenreich JE 2005 Gold as an implant in medicine and dentistry. J Long Term Eff Med Implants 15:687-698

6. Ratner BD, Bryant SJ 2004 Biomaterials: where we have been and where we are going. Annu Rev Biomed Eng 6:41-75

7. De Laporte L, Shea LD 2007 Matrices and scaffolds for DNA delivery in tissue engineering. Adv Drug Deliv Rev 59:292-307

8. Frimberger D, Lin HK, Kropp BP 2006 The use of tissue engineering and stem cells in bladder regeneration. Regen Med 1:425-435

9. Harrison BS, Eberli D, Lee SJ, Atala A, Yoo JJ 2007 Oxygen producing biomaterials for tissue regeneration. Biomaterials 28:4628-4634

10. Nakabayashi N 2003 Dental biomaterials and the healing of dental tissue. Biomaterials 24:2437-2439

11. Raghunath J, Rollo J, Sales KM, Butler PE, Seifalian AM 2007 Biomaterials and scaffold design: key to tissue-engineering cartilage. Biotechnol Appl Biochem 46:73-84

12. Earthman JC, Li Y, VanSchoiack LR, Sheets CG, Wu JC 2006 Reconstructive materials and bone tissue engineering in implant dentistry. Dent Clin North Am 50:229-244 ix.

13. Chalasani R, Poole-Warren L, Conway RM, Ben-Nissan B 2007 Porous orbital implants in enucleation: a systematic review. Surv Ophthalmol 52:145-155

14. Gilbert TW, Stewart-Akers AM, Badylak SF 2007 A quantitative method for evaluating the degradation of biologic scaffold materials. Biomaterials 28:147-150

15. van Amerongen MJ, Harmsen MC, Petersen AH, Kors G, van Luyn MJ 2006 The enzymatic degradation of scaffolds and their replacement by vascularized extracellular matrix in the murine myocardium. Biomaterials 27:2247-2257

16. Hollister SJ, Maddox RD, Taboas JM 2002 Optimal design and fabrication of scaffolds to mimic tissue properties and satisfy biological constraints. Biomaterials 23:4095-4103

17. Widmer MS, Gupta PK, Lu L, Meszlenyi RK, Evans GR, Brandt K, Savel T, Gurlek A, Patrick CW Jr, Mikos AG 1998 Manufacture of porous biodegradable polymer conduits by an extrusion process for guided tissue regeneration. Biomaterials 19:1945-1955

18. Gomes ME, Ribeiro AS, Malafaya PB, Reis RL, Cunha AM 2001 A new approach based on injection moulding to produce biodegradable starch-based polymeric scaffolds: morphology, mechanical and degradation behavior. Biomaterials 22:883889

19. Thornton AJ, Alsberg E, Hill EE, Mooney DJ 2004 Shape retaining injectable hydrogels for minimally invasive bulking. J Urol 172:763-768

20. Li X, Jin L, Balian G, Laurencin CT, Greg Anderson D 2006 Demineralized bone matrix gelatin as scaffold for osteochondral tissue engineering. Biomaterials 27:2426-2433

21. Patel M, Vandevord PJ, Matthew H, Wu B, DeSilva S, Wooley PH 2006 Video-gait analysis of functional recovery of nerve repaired with chitosan nerve guides. Tissue Eng 12:3189-3199

22. Perka C, Schultz O, Spitzer RS, Lindenhayn K, Burmester GR, Sittinger M 2000 Segmental bone repair by tissue-engineered periosteal cell transplants with bioresorable fleece and fibrin scaffolds in rabbits. Biomaterials 21:1145-1153

23. Sumita Y, Honda MJ, Ohara T, Tsuchiya S, Sagara H, Kagami H, Ueda M 2006 Performance of collagen sponge as a 3-D scaffold for tooth-tissue engineering. Biomaterials 27:3238-3248

24. Yoo HS, Lee EA, Yoon JJ, Park TG 2005 Hyaluronic acid modified biodegradable scaffolds for cartilage tissue engineering. Biomaterials 26:1925-1933

25. Richards SK, Lear PA, Huskisson L, Saleem MA, Morgan JD 2005 Porcine dermal collagen graft in pediatric renal transplantation. Pediatr Transplant 9:627-629

26. Esposito G, Gravante G, Filingeri V, Delogu D, Montone A 2007 Use of hyaluronan dressings following dermabrasion avoids escharectomy and facilitates healing in pediatric burn patients. Plast Reconstr Surg 119:2346-2347

27. Shin'oka T, Matsumura G, Hibino N, Naito Y, Watanabe M, Konuma T, Sakamoto T, Nagatsu M, Kurosawa H 2005 Midterm clinical result of tissue-engineered vascular autografts seeded with autologous bone marrow cells. J Thorac Cardiovasc Surg 129:1330-1338

28. Roh JD, Brennan MP, Lopez-Soler RI, Fong PM, Goyal A, Dardik A, Breuer CK 2007 Construction of an autologous tissue-engineered venous conduit from bone marrow-derived vascular cells: optimization of cell harvest and seeding techniques. J Pediatr Surg 42:198-202

29. Tuggle DW, Mantor PC, Foley DS, Markley MM, Puffinbarger N 2004 Using a bioabsorable copolymer plate for chest wall reconstruction. J Pediatr Surg 39:626628

30. Eppley BL, Morales L, Wood R, Pensler J, Goldstein J, Havlik RJ, Habal M, Losken A, Williams JK, Burstein F, Rozzelle AA, Sadove AM 2004 Resorbable PLLA-PGA plate and screw fixation in pediatric craniofacial surgery: clinical experience in 1883 patients. Plast Reconstr Surg 114:850-856; discussion 857

31. Ozawa T, Mickle DA, Weisel RD, Matsubayashi K, Fujii T, Fedak PW, Koyama N, Ikada Y, Li RK 2004 Tissue-engineered grafts matured in the right ventricular outflow tract. Cell Transplant 13:169-177 
32. Drewa T, Galazka P, Prokurat A, Wolski Z, Sir J, Wysocka K, Czajkowski R 2005 Abdominal wall repair using a biodegradable scaffold seeded with cells. J Pediatr Surg 40:317-321

33. Fisher JP, Jo S, Mikos AG, Reddi AH 2004 Thermoreversible hydrogel scaffolds for articular cartilage engineering. J Biomed Mater Res A 71:268-274

34. Kaihara S, Matsumura S, Fisher JP 2008 Synthesis and characterization of cyclic acetal based degradable hydrogels. Eur J Pharm Biopharm 68:67-73

35. Moreau JL, Kesselman D, Fisher JP 2007 Synthesis and properties of cyclic acetal biomaterials. J Biomed Mater Res A 81:594-602

36. Yoon DM, Fisher JP 2006 Chondrocyte signaling and artificial matrices for articular cartilage engineering. Adv Exp Med Biol 585:67-86

37. Yoon DM, Hawkins EC, Francke-Carroll S, Fisher JP 2007 Effect of construct properties on encapsulated chondrocyte expression of insulin-like growth factor-1. Biomaterials 28:299-306

38. Andriani E, Bugli T, Aalders M, Castelli S, De Luigi G, Lazzari N, Rolli GP 2000 [The effectiveness and acceptance of a medical device for the treatment of aphthous stomatitis. Clinical observation in pediatric age]. Minerva Pediatr 52:15-20

39. Ruszymah BH, Chua K, Latif MA, Hussein FN, Saim AB 2005 Formation of in vivo tissue engineered human hyaline cartilage in the shape of a trachea with internal support. Int J Pediatr Otorhinolaryngol 69:1489-1495

40. Kobus KF 2007 Cleft palate repair with the use of osmotic expanders: a preliminary report. J Plast Reconstr Aesthet Surg 60:414-421

41. Schittkowski MP, Guthoff RF 2006 Injectable self inflating hydrogel pellet expanders for the treatment of orbital volume deficiency in congenital microphthalmos: preliminary results with a new therapeutic approach. Br J Ophthalmol 90:1173-1177

42. Bendoriene J, Vogt U 2006 Therapeutic use of silicone hydrogel contact lenses in children. Eye Contact Lens 32:104-108

43. Maurer BJ, Kalous O, Yesair DW, Wu X, Janeba J, Maldonado V, Khankaldyyan V, Frgala T, Sun BC, McKee RT, Burgess SW, Shaw WA, Reynolds CP 2007 Improved oral delivery of N-(4-hydroxyphenyl)retinamide with a novel LYM-XSORB organized lipid complex. Clin Cancer Res 13:3079-3086

44. Cohen AJ, Dickerman RD, Schneider SJ 2004 New method of pediatric cranioplasty for skull defect utilizing polylactic acid absorbable plates and carbonated apatite bone cement. J Craniofac Surg 15:469-472
45. Velardi F, Amante PR, Caniglia M, De Rossi G, Gaglini P, Isacchi G, Palma P, Procaccini E, Zinno F 2006 Osteogenesis induced by autologous bone marrow cells transplant in the pediatric skull. Childs Nerv Syst 22:1158-1166

46. Sunil I, Bond SJ, Nagaraj HS 2006 Primitive neuroectodermal tumor of the sternum in a child: resection and reconstruction. J Pediatr Surg 41:e5-e8

47. Nikitin AA, Titova NV, Karachunskii GM 2005 [Surgical treatment of cystous lesions of the jaws in children using biocomposite material]. Stomatologiia (Mosk) $84: 40-43$

48. Perry TE, Kaushal S, Sutherland FW, Guleserian KJ, Bischoff J, Sacks M, Mayer JE 2003 Thoracic Surgery Directors Association Award. Bone marrow as a cell source for tissue engineering heart valves. Ann Thorac Surg 75:761-767; discussion 767

49. Schmidt D, Breymann C, Weber A, Guenter CI, Neuenschwander S, Zund G, Turina M, Hoerstrup SP 2004 Umbilical cord blood derived endothelial progenitor cells for tissue engineering of vascular grafts. Ann Thorac Surg 78:2094-2098

50. Sodian R, Lueders C, Kraemer L, Kuebler W, Shakibaei M, Reichart B, Daebritz S, Hetzer R 2006 Tissue engineering of autologous human heart valves using cryopreserved vascular umbilical cord cells. Ann Thorac Surg 81:2207-2216

51. Stuart JD, Kenney JG, Morgan RF 1987 Pediatric burns. Am Fam Physician 36:139-146

52. Cassidy C, St Peter SD, Lacey S, Beery M, Ward-Smith P, Sharp RJ, Ostlie DJ 2005 Biobrane versus duoderm for the treatment of intermediate thickness burns in children: a prospective, randomized trial. Burns 31:890-893

53. Lang EM, Eiberg CA, Brandis M, Stark GB 2005 Biobrane in the treatment of burn and scald injuries in children. Ann Plast Surg 55:485-489

54. Martinez L, Ros Z, Lopez-Gutierrez JC, Diaz M, Quezada B, Perdiguero M, Hernandez F, Rivas S, Tovar JA 2002 [Integra artificial dermis in pediatric reconstructive surgery]. Cir Pediatr 15:97-100

55. Kumar RJ, Kimble RM, Boots R, Pegg SP 2004 Treatment of partial-thickness burns: a prospective, randomized trial using Transcyte. ANZ J Surg 74:622-626

56. Norbury WB, Jeschke MG, Herndon DN 2005 Tissue engineered fetal skin constructs for pediatric burns. Crit Care 9:533-534 